University of Wollongong

Research Online

Australian Institute for Innovative Materials -

Papers

Australian Institute for Innovative Materials

$1-1-2017$

\title{
A Biodegradable Thin-Film Magnesium Primary Battery Using Silk Fibroin- Ionic Liquid Polymer Electrolyte
}

Xiaoteng Jia

University of Wollongong, xj916@uowmail.edu.au

Caiyun Wang

University of Wollongong, caiyun@uow.edu.au

Vijayaraghavan Ranganathan

Monash University

Bradley Napier

Tufts University

Changchun $\mathrm{Yu}$

University of Wollongong, cy470@uowmail.edu.au

See next page for additional authors

Follow this and additional works at: https://ro.uow.edu.au/aiimpapers

Part of the Engineering Commons, and the Physical Sciences and Mathematics Commons

Research Online is the open access institutional repository for the University of Wollongong. For further information contact the UOW Library: research-pubs@uow.edu.au 


\title{
A Biodegradable Thin-Film Magnesium Primary Battery Using Silk Fibroin-Ionic Liquid Polymer Electrolyte
}

\author{
Abstract \\ Transient implantable medical bionics offer great promise in the field of smart controlled release and \\ tissue regeneration. On-board energy storage is the ideal power system to drive them. In this work, a \\ critical component of such a device, a biodegradable polymer electrolyte (silk fibroin-choline nitrate) has \\ been developed. The efficiency of this electrolyte is demonstrated when deployed in a biodegradable thin- \\ film magnesium battery. The battery, encapsulated in silk, offers a specific capacity of $0.06 \mathrm{mAh} \mathrm{cm-2}$. \\ The enzymatic degradation of the whole device occurs over 45 days in the buffered protease XIV solution. \\ A programmed battery lifetime can be achieved using silk protection layers. This battery system provides \\ a new avenue for an on-board biodegradable power source for next-generation transient medical bionics.

\section{Disciplines \\ Engineering | Physical Sciences and Mathematics}

\section{Publication Details} \\ Jia, X., Wang, C., Ranganathan, V., Napier, B., Yu, C., Chao, Y., Forsyth, M., Omenetto, F. G., MacFarlane, D. R. \\ \& Wallace, G. G. (2017). A Biodegradable Thin-Film Magnesium Primary Battery Using Silk Fibroin-lonic \\ Liquid Polymer Electrolyte. ACS Energy Letters, 2 (4), 831-836.
}

\section{Authors}

Xiaoteng Jia, Caiyun Wang, Vijayaraghavan Ranganathan, Bradley Napier, Changchun Yu, Yunfeng Chao, Maria Forsyth, Fiorenzo Omenetto, Douglas R. MacFarlane, and Gordon G. Wallace 


\section{A Biodegradable Thin-Film Magnesium Primary Battery using Silk Fibroin-Ionic}

\section{Liquid Polymer Electrolyte}

Xiaoteng Jia ${ }^{a}$, Caiyun Wang $^{a *}$, Vijayaraghavan Ranganathan ${ }^{b}$, Bradley Napier ${ }^{c}$, Changchun Yu ${ }^{a}$, Yunfeng Chao ${ }^{a}$, Maria Forsyth ${ }^{d}$, Fiorenzo G. Omenetto ${ }^{c}$, Douglas R. MacFarlane ${ }^{b}$, Gordon G. Wallace $e^{*}$

a. ARC Centre of Excellence for Electromaterials Science, Intelligent Polymer Research Institute, AIIM Faculty, University of Wollongong, Wollongong, NSW 2522, Australia.

b. ARC Centre of Excellence for Electromaterials Science, School of Chemistry, Monash University, Clayton, Victoria 3800, Australia.

c. Silklab, Department of Biomedical Engineering, Tufts University, Medford, Massachusetts 02155, United States.

d. ARC Centre of Excellence for Electromaterials Science, Institute for Frontier Materials, Deakin University, Burwood, Victoria 3125, Australia.

Corresponding Authors

E-mail: caiyun@uow.edu.au (C.W.), gwallace@uow.edu.au (G.G.W.). 


\begin{abstract}
Transient implantable medical bionics offer great promise in the field of smart controlled release and tissue regeneration. On-board energy storage is the ideal power system to drive them. In this work, a critical component of such a device, a biodegradable polymer electrolyte (silk fibroin-choline nitrate) has been developed. The efficiency of this electrolyte is demonstrated when deployed in a biodegradable thin-film magnesium battery. The battery, encapsulated in silk, offers a specific capacity of $0.06 \mathrm{mAh} \mathrm{cm}{ }^{-2}$. The enzymatic degradation of the whole device occurred over 45 days in the buffered protease XIV solution. A programmed battery lifetime can be achieved using silk protection layers. This battery system provides a new avenue for on-board biodegradable power source for next generation transient medical bionics.
\end{abstract}

\title{
TOC figure
}
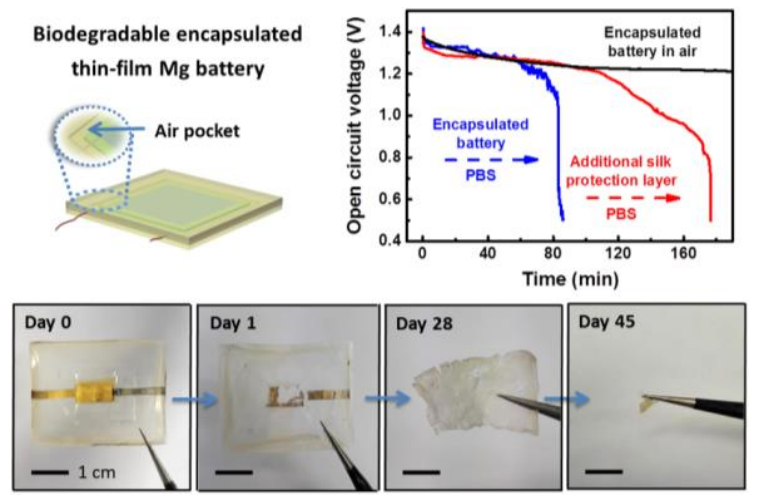
Transient implantable medical bionics (TIMBs) which feature a complete disappearance in a controlled manner after their operation are gaining ground. ${ }^{1}$ They provide the ability to influence biological processes in a controlled fashion., ${ }^{2,3}$ This has implications for areas such as wound healing, bone fracture and tissue regeneration. Such systems involve the use of electrical stimulation to perform the function. Current demonstrations have typically been limited by the use of an external power source or a wireless powering system. ${ }^{4}$ Here we present an alternative approach involving an implantable battery system that satisfies the power requirements of the TIMB and then harmlessly degrades. To date, only a few studies have attempted to fabricate biodegradable batteries. One option is to employ biologically derived melanin pigment as an electrode which could reversibly bind sodium and magnesium ( $\mathrm{Mg}$ ) cations. ${ }^{5,6}$ Another strategy utilizes a bioresorbable $\mathrm{Mg}$ anode coupled with biocompatible metallic cathodes such as iron and molybdenum ${ }^{7}$ The major challenge facing these aqueous batteries is their integration with the electronic systems (sensors and bioelectronics) within a TIMB. ${ }^{8}$

In this study, we report on a biodegradable thin-film $\mathrm{Mg}$ battery using a silk fibroin-choline nitrate $\left(\mathrm{SF}-[\mathrm{Ch}]\left[\mathrm{NO}_{3}\right]\right)$ polymer electrolyte $(\mathrm{PE})$. Silk fibroin $(\mathrm{SF})$ is a naturally occurring biodegradable protein fiber and a promising candidate for electronic implants interfaced with human body. ${ }^{9,10}$ The use of regenerated SF lies in the fact that it possesses the ability to entrap or stabilize chemical or biologically active molecules, allowing the addition of a new function. ${ }^{11}$ Ionic liquids (ILs) are molten salts at ambient temperature that are currently being used as solvents or additives for biopolymers. When used as electrolytes they possess the advantages: a wide and stable electrochemical potential window, high ionic conductivity and in some cases good biocompatibility. ${ }^{12}$ Degummed silk fibers can be dissolved in ILs and processed into different forms after the extraction of the IL. ${ }^{13}$ Here we demonstrate the use of SF to immobilize an IL and form a free-standing membrane, harnessing both the biological activity of SF and the ionic conductivity of the IL. 
In this work a biocompatible IL (choline nitrate, $\left.[\mathrm{Ch}]\left[\mathrm{NO}_{3}\right]\right)^{14}$ was immobilized in silk to form a biodegradable ion-conducting membrane. Different amounts of $[\mathrm{Ch}]\left[\mathrm{NO}_{3}\right]$ were introduced into $\mathrm{SF}$ aqueous solution, the weight ratios of $\mathrm{SF}$ to $[\mathrm{Ch}]\left[\mathrm{NO}_{3}\right]$ used were 1:1, 1:5 and 1:9. At all ratios investigated, the $[\mathrm{Ch}]\left[\mathrm{NO}_{3}\right] / \mathrm{SF}$ solutions are miscible during long-term (up to six weeks) storage (Figure 1a). The Fourier-transform infrared spectra (FTIR) (Figure 1b) exhibited the expected absorbance bands at $1650 \mathrm{~cm}^{-1}$ and $1236 \mathrm{~cm}^{-1},{ }^{15}$ corresponding to the silk I structure, as well as bands at $1330 \mathrm{~cm}^{-1}$ (vibration of $\mathrm{NO}_{3}{ }^{-}$) and $954 \mathrm{~cm}^{-1}$ (vibration of $\mathrm{C}-\mathrm{C}-\mathrm{OH})$ due to the presence of IL. As the content of $[\mathrm{Ch}]\left[\mathrm{NO}_{3}\right]$ was increased, the intensity of the amide I shoulder at $1630 \mathrm{~cm}^{-1}$ increased, indicating a crystallinity enhancement. ${ }^{16}$ A protein conformation transition from random coil and/or helical structure to $\beta$-sheet can be ascribed to IL binding to the protein surface and increasing surface tension. ${ }^{17}$ This behaviour is similar to that observed for SF interacting with metallic cations. ${ }^{18}$ The coordination of cations to the carbonyl and/or $\mathrm{OH}$ group of SF could affect the hydrogen bonding interactions in SF and consequently its secondary structure. Thermogravimetric analysis (Figure S1, Supporting Information) revealed the amount of water confined in the PE was $5-9 \%(\mathrm{w} / \mathrm{w})$. This acts as a proton source to support the oxygen reduction reaction (ORR) at the cathode. ${ }^{19}$

The silk film exhibited a tensile strength of $21 \mathrm{MPa}$ with an $8 \%$ elongation to break (Figure 1c). Addition of IL to obtain a PE composition of (SF: $[\mathrm{Ch}]\left[\mathrm{NO}_{3}\right]$, weight ratio of $\left.1: 3\right)$ resulted in decreased mechanical strength $(2.0 \mathrm{MPa})$ but an enhanced ductility, producing a $98 \%$ elongation to break. The inclusion of $[\mathrm{Ch}]\left[\mathrm{NO}_{3}\right]$ weakens the hydrogen bonding interactions between glycine and alanine in the crystalline region and enhances segmental motion, thereby increasing the overall flexibility of the material. ${ }^{20}$ The plasticizing effect was also observed by the addition of glycerol in SF due to the formation of hydrogen bonds between the hydroxyl $(\mathrm{OH})$ group of glycerol and the hydrophilic polar groups present in some amino acids. ${ }^{21}$ However, when the $[\mathrm{Ch}]\left[\mathrm{NO}_{3}\right]$ content was further increased to a weight ratio of 1:5 
(SF: $[\mathrm{Ch}]\left[\mathrm{NO}_{3}\right]$ ), the mechanical strength was lowered to $1.2 \mathrm{MPa}$ and the elongation to break was also reduced to $81 \%$. The effect of $[\mathrm{Ch}]\left[\mathrm{NO}_{3}\right]$ addition on ionic conductivity was also determined (Figure 1d). The conductivity was $0.85 \mathrm{mS} \mathrm{cm}^{-1}$ for the $1: 1$ composite, and increased to $3.4 \mathrm{mS} \mathrm{cm}^{-1}$ for a 1:3 composite. This is attributed to the strong plasticizing effect of the IL and the inherent high ionic conductivity of the IL. ${ }^{22}$ A further increase of $[\mathrm{Ch}]\left[\mathrm{NO}_{3}\right]$ to $1: 5$ resulted in an even higher ionic conductivity of $7.4 \mathrm{mS} \mathrm{cm} \mathrm{cm}^{-1}$. However, some IL component may potentially separate from the PE when it contains such high amounts. ${ }^{23}$ Thus SF- $[\mathrm{Ch}]\left[\mathrm{NO}_{3}\right]$ (weight ratio of 1:3) was chosen for further studies for its combination of ionic conductivity and mechanical properties (Table S1, Supporting Information).

a

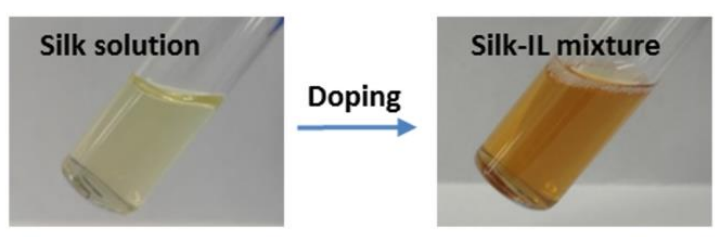

\section{Electrolyte film}
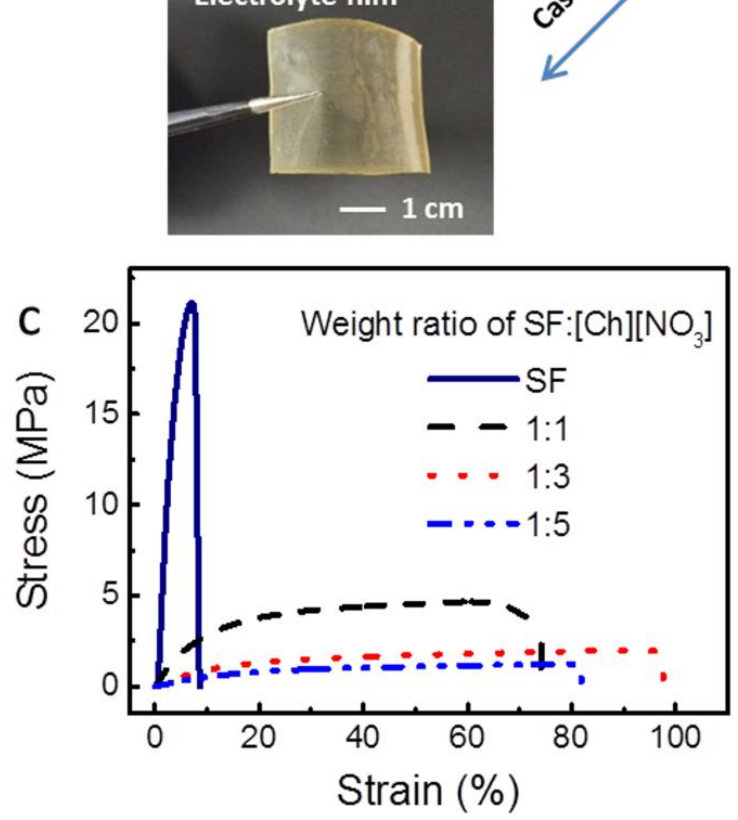
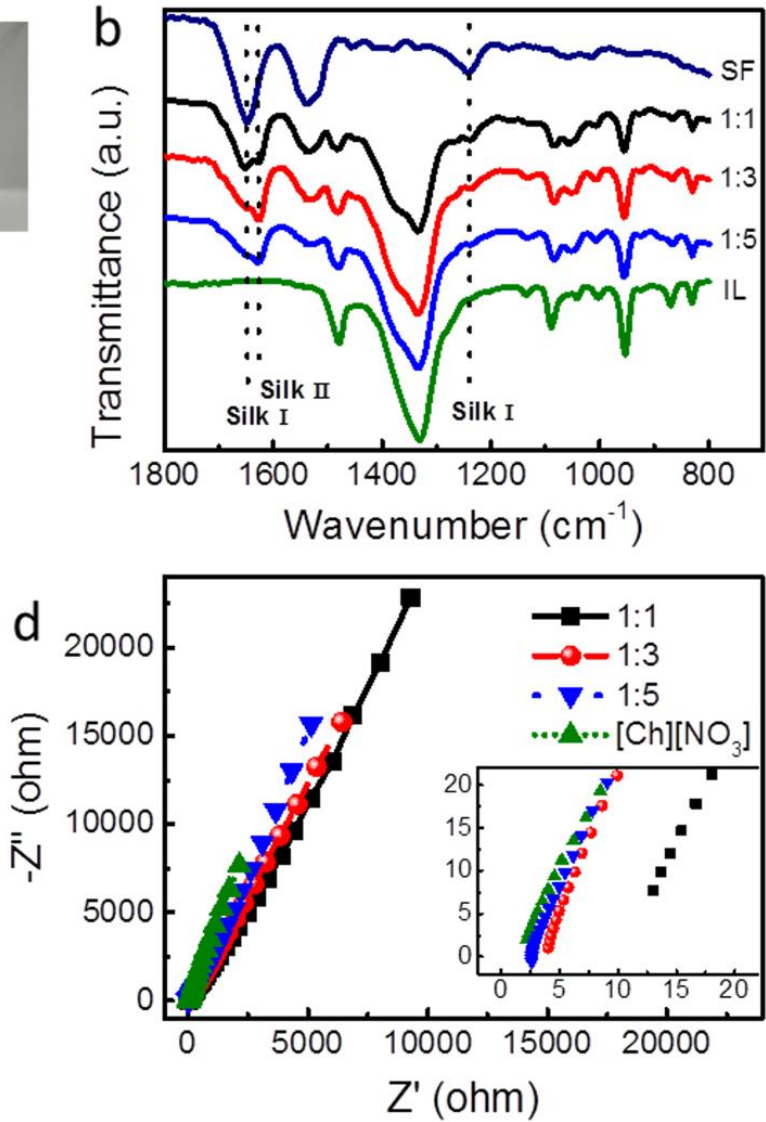

Figure 1. (a) Fabrication procedures and a digital image of a PE film (SF: $[\mathrm{Ch}]\left[\mathrm{NO}_{3}\right]$, weight ratio of 1:3). FTIR spectra (b), Stress-strain curves (c) and AC impedance spectra (d) of PE 
containing different amount of $[\mathrm{Ch}]\left[\mathrm{NO}_{3}\right]$ (Inset of Figure 1d, expanded view at high frequency region).

Biodegradation of the SF- $[\mathrm{Ch}]\left[\mathrm{NO}_{3}\right]$ film was investigated in a buffered protease $\mathrm{XIV}$ solution, with phosphate buffered saline (PBS) solution as a control. The weight loss was 68\% in PBS after 24 h exposure (Figure 2a). The PE film retained $22 \%$ of its initial weight after 5 days, close to the content of SF component $(23 \%)$. The weight loss was mainly attributed to IL migrating from the polymer matrix into solution. This is a reflection of $[\mathrm{Ch}]\left[\mathrm{NO}_{3}\right]$ not being tightly bound to the SF host matrix, but being highly mobile, which was also evidenced by the concomitantly sharp decrease in ionic conductivity from 3.4 to $0.03 \mathrm{mS} \mathrm{cm}^{-1}$ after incubation in PBS for $12 \mathrm{~h}$ (Figure 2b). In the enzyme solution, the weight loss was $89 \%$ after $24 \mathrm{~h}$, much higher than that $(68 \%)$ in PBS. In this case the degradation of silk I and/or amorphous structure was involved. ${ }^{24}$ The PE disintegrated after 2 days. Structural changes after $24 \mathrm{~h}$ degradation in the enzyme and PBS were investigated by FTIR. The characteristic peaks from $[\mathrm{Ch}]\left[\mathrm{NO}_{3}\right]$ were not observed for these two samples (Figure 2c), a clear demonstration of the disappearance of IL thus matching the biodegradation results. The PE retained the structure of silk I in PBS, whereas the intensity of the amide I shoulder at 1630 $\mathrm{cm}^{-1}$ increased in enzyme solution. This slight increase in the $\beta$-sheet crystalline region was probably due to the digestion of silk I and/or non-crystalline region of silk component by the action of protease. ${ }^{25}$ To further understand this degradation process, changes in the surfaces morphologies were monitored. The PE film was of smooth and uniform surface. After $24 \mathrm{~h}$ degradation, a textured, microporous structure created by IL leaching was developed in PBS, whereas the film was degraded into small fragments in the enzyme solution. 

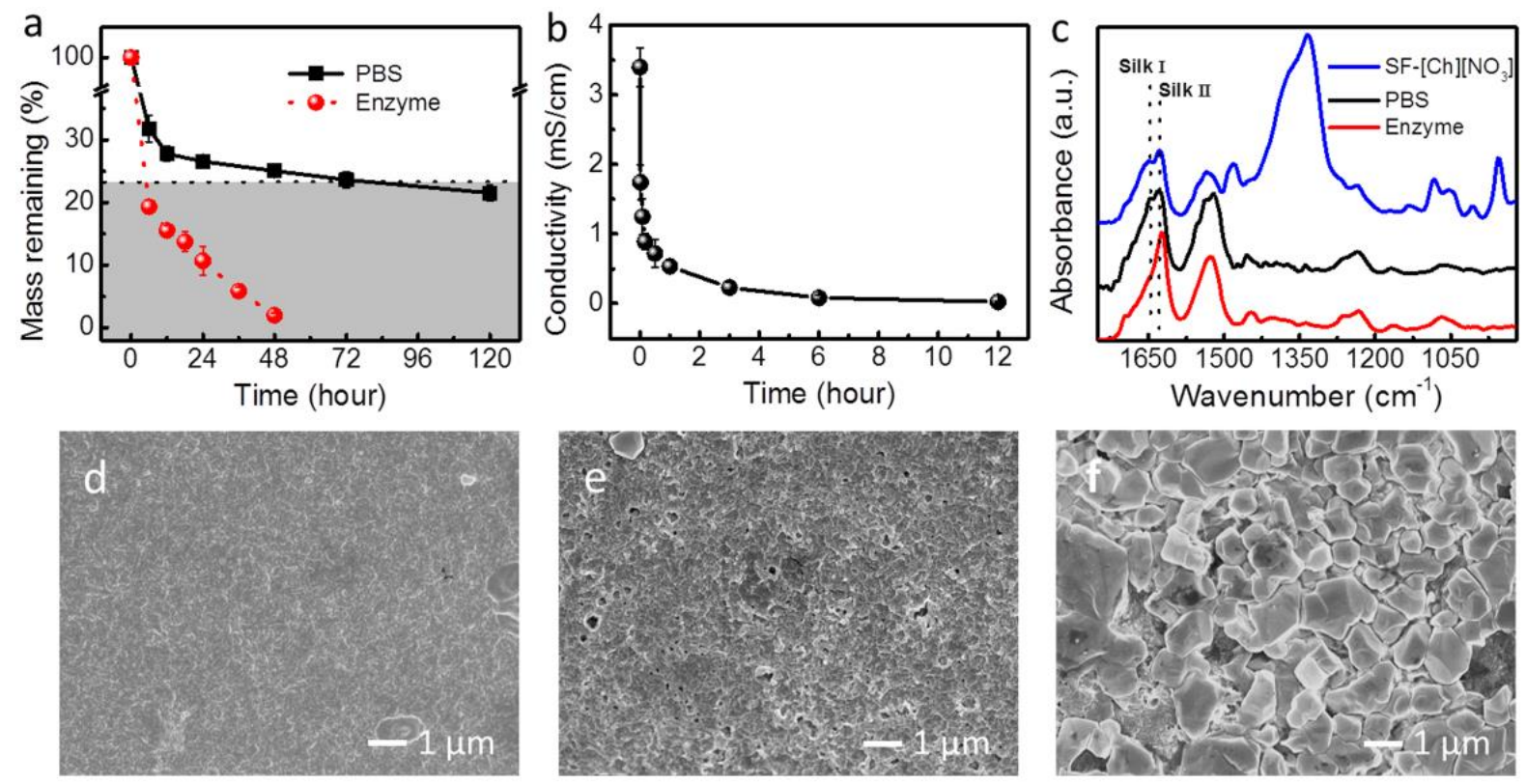

Figure 2. Degradation behaviour of SF-[Ch] $\left[\mathrm{NO}_{3}\right]$ (weight ratio of 1:3) PE. (a) Mass loss in protease XIV solution and PBS (bars represent standard deviation, $n=3$ ); The dashed line represents the content of SF in PE. (b) Conductivity change upon $12 \mathrm{~h}$ exposure in PBS. (c) FTIR spectra before and after exposure in PBS and enzyme solution for $24 \mathrm{~h}$; SEM images before exposure (d), after exposure in PBS (e) and enzyme (f) solution for $24 \mathrm{~h}$.

$\mathrm{Mg}$ or its alloys, including AZ31, have been suggested as the sacrificial anodes for biodegradable batteries due to a high theoretical capacity, acceptable dissolution rate and favourable biocompatibility. ${ }^{26}$ This electrolyte showed an electrochemical window of up to 2.3 V (Figure S2, Supporting Information), which was sufficiently high for use in a $\mathrm{Mg}$ primary battery. As a bio-inert noble metal and catalyst towards $\mathrm{ORR},{ }^{27}$ a $100 \mathrm{~nm}$ layer of gold nanoparticles was physically deposited onto a crystallized silk film (Au-SF). This battery system, AZ31|SF-[Ch] $\left[\mathrm{NO}_{3}\right] \mid \mathrm{Au}-\mathrm{SF}$, is a metal-air battery. The main discharge reactions involved are as follows: ${ }^{28}$

Anode: $2 \mathrm{Mg}+4 \mathrm{OH}^{-} \rightarrow 2 \mathrm{Mg}(\mathrm{OH})_{2}+4 \mathrm{e}^{-}(E=-2.69 \mathrm{~V})$

Cathode: $\mathrm{O}_{2}+2 \mathrm{H}_{2} \mathrm{O}+4 \mathrm{e}^{-} \rightarrow 4 \mathrm{OH}^{-}(E=0.40 \mathrm{~V})$

Overall reaction: $2 \mathrm{Mg}+\mathrm{O}_{2}+2 \mathrm{H}_{2} \mathrm{O} \rightarrow 2 \mathrm{Mg}(\mathrm{OH})_{2}\left(E_{\text {cell }}=3.09 \mathrm{~V}\right)$ 
The anion in the polymer electrolyte may also participate in the reaction with $\mathrm{Mg}$ alloy forming magnesium nitrate, and results in a decreased conductivity after discharge.

The open circuit voltages $(\mathrm{OCV})$ for the AZ31|SF-[Ch] $\left[\mathrm{NO}_{3}\right] \mid \mathrm{Au}-\mathrm{SF}$ battery were in the range of 1.58-1.45 V just after the cell was assembled (Figure S3, Supporting Information). The cell voltage dropped immediately when a discharge current was applied and soon reached a flat discharge plateau. At a current density of $5 \mu \mathrm{A} \mathrm{cm}^{-2}$, the battery displayed a capacity of 2.2 mAh $\mathrm{cm}^{-2}$ with a plateau voltage of $\sim 1.03 \mathrm{~V}$ (middle point of the discharge curve). This battery could deliver a maximum volumetric power density of $1.07 \mathrm{~W} \mathrm{~L}^{-1}$ and an energy density of $70.9 \mathrm{Wh} \mathrm{L}^{-1}$ based on a dimension of whole device $\left(1 \times 1 \times 0.032 \mathrm{~cm}^{3}\right)$. The battery using a stainless steel (SS) mesh cathode displayed a significantly decreased performance in plateau voltage and discharge time $(0.75 \mathrm{~V}, 9 \mathrm{~h})$, compared to those $(0.86 \mathrm{~V}, 61 \mathrm{~h})$ for Au-SF cathode at the same current density of $20 \mu \mathrm{A} \mathrm{cm}^{-2}$; confirming the catalytic role of the Au-SF cathode (Figure S4, Supporting Information).

To further reduce the battery thickness and impart a soft nature to the anode as well, we fabricated anodes by sputtering AZ31 onto crystallized silk films (AZ31-SF) to substitute for the stiff AZ31 foil. Such thin-film electrode could minimize mechanical injury associated with implantation and chronic use. This silk-based battery was further encapsulated by a thermal processing (Figure 3a). ${ }^{4,29}$ To avoid the mechanical stress on electrodes and PE, only the outer edges around the battery were laminated with an amorphous silk adhesive frame between the electrodes. ${ }^{30}$ This frame is of the same size as the silk substrate, far larger than that of electrodes and electrolyte. This process could create a small air pocket, providing air for the cathode reaction. Figure $3 b$ shows the evaluation of the effect of AZ31 thin-film thickness on the performance of encapsulated batteries. As expected, batteries with thicker AZ31 thin-films displayed longer discharge times. The battery with a $500 \mathrm{~nm}$ AZ31 layer could deliver a specific capacity of $0.06 \mathrm{mAh} \mathrm{cm}^{-2}$ at a current density of $10 \mu \mathrm{A} \mathrm{cm} \mathrm{cm}^{-2}$, but significantly lower than that from an unsealed battery with an AZ31 foil anode $\left(1.43 \mathrm{mAh} \mathrm{\textrm {cm } ^ { - }}\right.$ 
${ }^{2}$ ). The rapid depletion of the active AZ31 coating and the limited oxygen available may be the main reasons for this discrepancy. The encapsulated battery achieved a coulombic efficiency of $27 \%$. Nevertheless, the power offered $\left(8.7 \mu \mathrm{W} \mathrm{cm}{ }^{-2}\right)$ may fulfil the requirements for average consumption of published wireless implantable sensing systems $(<0.5 \mathrm{~V},<0.5$ $\mu \mathrm{W}) .{ }^{31}$ This air pre-loaded strategy was advantageous for batteries when implanted in the sites with limited availability of oxygen. The encapsulated battery exhibited a bulk resistance of $\sim 11.5 \mathrm{ohm}$ (Figure S5, Supporting Information), indicating good contact and low resistance in the cell.

A particular challenge for biodegradable batteries exists in controlling the battery lifetime and correlating it with TIMBs when exposed to physiological conditions. Adding an additional crystallized silk film on top of an encapsulated battery can extend its lifetime (Figure S6, Supporting Information). Crystallized silk films can serve as non-immunogenic diffusion barriers for water influx. ${ }^{32}$ The modulated degradation profile of encapsulated batteries via multilayer silk films is demonstrated in Figure 3c. An encapsulated battery (single protection layer) showed a stable OCV (1.21 V) in air with $11 \%$ of self-discharge loss after $180 \mathrm{~min}$, likely due to the corrosion of the AZ31 layer at the interface with the PE. When exposed to PBS, a two-stage transient behaviour was observed: a stable OCV above $1.21 \mathrm{~V}$ for $64 \mathrm{~min}$ (i.e. same discharge profile as in air), followed by a rapid functional degradation in 22 min. This discharge profile can be explained by the protection afforded by the crystallized silk film; the silk film absorbed water and began to swell, with liquid water being held within the swollen film, thus the device behaved as it would in the absence of water. In the second stage, the water penetration through the hydrated silk films led to the fast degradation as the AZ31 thin-film rapidly dissolved and IL leached from the PE. An additional silk protection layer over the encapsulated battery resulted in an extension of the stable operating stage to $109 \mathrm{~min}$ and the subsequent functional degradation to $68 \mathrm{~min}$. These results clearly demonstrate that the device degradation profile can be simply modulated by the silk protection layer/layers. It 
can be envisioned that control over silk film thickness and its crystallinity (e.g. $\beta$-sheet content) can further tune the degradation profile. $^{33}$

A biodegradation study was performed to demonstrate that this whole battery system can indeed decompose (Figure 3d). The biodegradation process of an encapsulated battery is determined by the slow SF degradation by proteolytic activity, which can be regulated by changing crystallinity and molecular weight. ${ }^{34}$ A thin-film AZ31 dissolution process via hydrolysis also occurred forming mainly $\mathrm{Mg}(\mathrm{OH})_{2}$, at a rate of $0.02-0.1 \mu \mathrm{m} \mathrm{h}^{-1}$ in simulated body fluids. ${ }^{35}$ In this encapsulated battery, AZ31 thin-film (500 nm thickness) completely disappeared in $4 \mathrm{~h}$, whereas the overall encapsulated battery (170 $\mu \mathrm{m}$ thickness) nearly totally degraded after 45 days. The Au component (0.09 mg/230 mg device) was physically fragmented in the solution due to the degradation of the silk substrate. Au nanoparticles was considered to be safe owing to its inert nature, extreme resistance to oxidation and considerable biocompatibility. ${ }^{36}$ If SF-Au film could be further degraded into several hundred nanometer pieces under optimized enzyme treatment, gold nanoparticles may be eventually cleared by renal excretion, phagocytosis and/or endocytosis. 

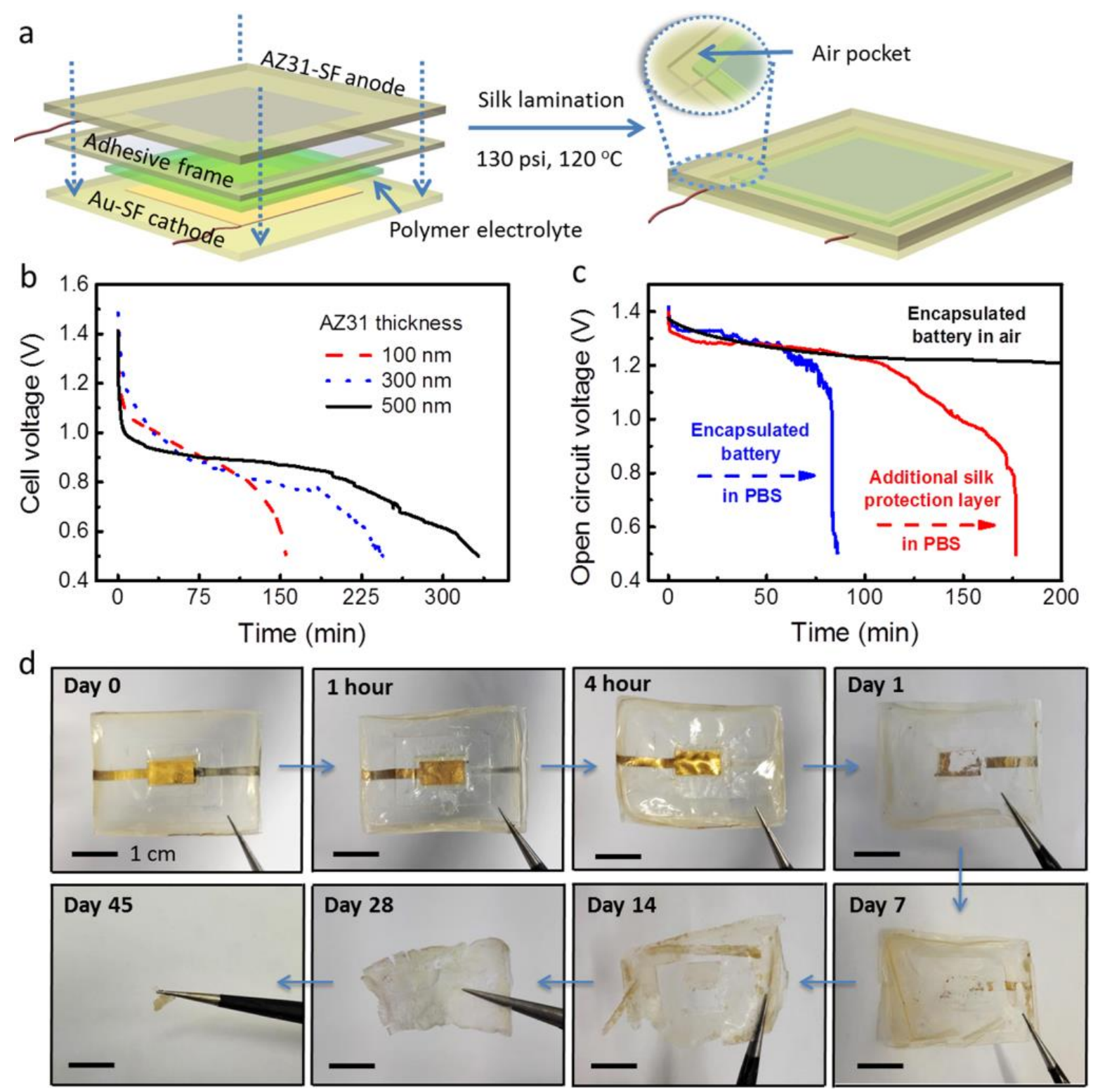

Figure 3. Device structure, discharge performance and biodegradation profile of an encapsulated Mg thin-film battery. a) Schematic of an encapsulated battery with a silk pocket. b) Effect of AZ31 thin-film thickness on the discharge performance of an encapsulated battery at a current density of $10 \mu \mathrm{A} \mathrm{cm} \mathrm{cm}^{-2}$. c) In situ OCV changes of an encapsulated battery (AZ31 thickness $500 \mathrm{~nm}$ ) and with an additional silk protection layer exposed to air and $1 \mathrm{~mL}$ PBS. d) Optical images demonstrating the biodegradation profile of an encapsulated battery (device size of $3.6 \times 2.7 \times 0.017 \mathrm{~cm}^{3}$ ) in buffered protease solution at $37{ }^{\circ} \mathrm{C}$.

In summary, we demonstrate a silk-based compact $\mathrm{Mg}$ battery entirely made of biocompatible and biodegradable materials. By introducing a biocompatible IL into a silk solution, the 


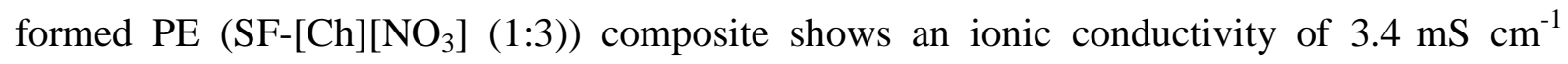
coupled with a two-day degradation profile in concentrated buffered protease solution. The encapsulated thin-film battery offers a capacity of $0.06 \mathrm{mAh} \mathrm{cm}^{-2}$ at a current density of 10 $\mu \mathrm{A} \mathrm{cm}{ }^{-2}$, and an almost full-degradation profile of 45 days when incubated in the protease solution. The battery lifetime upon exposure to PBS can be tuned using silk protection layers. It is anticipated that tailoring the properties of silk layers can further modulate the degradation profile and lead to a predictable/programmed battery lifetime. This work may provide additional avenues for on-board energy storage systems on a single chip of silk for the next generation of TIMBs, such as required for tissue regeneration.

\section{Supporting Information}

Brief statements of experimental method for electrolyte preparation and cell construction, and electrochemical testing.

\section{Author information}

Corresponding Authors

E-mail: caiyun@uow.edu.au (C.W.), gwallace@uow.edu.au (G.G.W.).

Notes

The authors declare no competing financial interest.

\section{Acknowledgements}

Funding from the Australian Research Council Centre of Excellence Scheme (Project Number CE 140100012) is gratefully acknowledged. G. G. W., M. F., and D. R. M. are grateful to the ARC for support under the Australian Laureate Fellowship scheme FL110100196, FL110100013 and FL120100019 respectively. The authors would like to thank the Australian National Fabrication Facility (ANFF)-Materials Node and the UoW 
Electron Microscopy Centre for equipment use. F. G. O. acknowledges funding from the Office of Naval Research (N00014-13-1-0596).

\section{References}

(1) Boutry, C. M.; Chandrahalim, H.; Streit, P.; Schinhammer, M.; Hänzi, A. C.; Hierold, C. Towards biodegradable wireless implants Phil. Trans. R. Soc. A 2012, 370, 2418-2432.

(2) Bettinger, C. J.; Bao, Z. Organic thin-film transistors fabricated on resorbable biomaterial substrates Adv. Mater. 2010, 22, 651-655.

(3) Irimia-Vladu, M. 'Green', electronics: biodegradable and biocompatible materials and devices for sustainable future Chem. Soc. Rev. 2014, 43, 588-610.

(4) Tao, H.; Hwang, S. W.; Marelli, B.; An, B.; Moreau, J. E.; Yang, M.; Brenckle, M. A.; Kim, S.; Kaplan, D. L.; Rogers, J. A.; Omenetto, F. G. Silk-based resorbable electronic devices for remotely controlled therapy and in vivo infection abatement Proc. Natl. Acad. Sci. U. S. A. 2014, 111, 17385-17389.

(5) Kim, Y. J.; Wu, W.; Chun, S. E.; Whitacre, J. F.; Bettinger, C. J. Biologically derived melanin electrodes in aqueous sodium-ion energy storage devices Proc. Natl. Acad. Sci. U. S. A. 2013, 110, 20912-20917.

(6) Kim, Y. J.; Wu, W.; Chun, S. E.; Whitacre, J. F.; Bettinger, C. J. Catechol-mediated reversible binding of multivalent cations in eumelanin half-cells Adv. Mater. 2014, 26, 65726579.

(7) Yin, L.; Huang, X.; Xu, H.; Zhang, Y.; Lam, J.; Cheng, J.; Rogers, J. A. Materials, designs, and operational characteristics for fully biodegradable primary batteries Adv. Mater. 2014, 26, 3879-3884.

(8) Heller, A. Potentially implantable miniature batteries Anal. Bioanal. Chem. 2006, 385, $469-473$ 
(9) Tao, H.; Kaplan, D. L.; Omenetto, F. G. Silk materials-a road to sustainable high technology Adv. Mater. 2012, 24, 2824-2837.

(10) Omenetto, F. G.; Kaplan, D. L. New opportunities for an ancient material Science 2010, $329,528-531$.

(11) Pritchard, E. M.; Dennis, P. B.; Omenetto, F.; Naik, R. R.; Kaplan, D. L. Physical and chemical aspects of stabilization of compounds in silk Biopolymers 2012, 97, 479-498.

(12) Ueki, T.; Watanabe, M. Macromolecules in ionic liquids: progress, challenges, and opportunities Macromolecules 2008, 41, 3739-3749.

(13) Phillips, D. M.; Drummy, L. F.; Conrady, D. G.; Fox, D. M.; Naik, R. R.; Stone, M. O.; Trulove, P. C.; De Long, H. C.; Mantz, R. A. Dissolution and regeneration of bombyx mori silk fibroin using ionic liquids J. Am. Chem. Soc. 2004, 126, 14350-14351.

(14) Weaver, K. D.; Kim, H. J.; Sun, J.; MacFarlane, D. R.; Elliott, G. D. Cyto-toxicity and biocompatibility of a family of choline phosphate ionic liquids designed for pharmaceutical applications Green Chem. 2010, 12, 507-513.

(15) Wilson, D.; Valluzi, R.; Kaplan, D. Conformational transitions in model silk peptides Biophys. J. 2000, 78, 2690-2701.

(16) Pereira, R. F. P.; Sentanin, F.; Pawlicka, A.; Goncalves, M. C.; Silva, M. M.; Bermudez, V. Z. Smart windows prepared from bombyx mori silk ChemElectroChem 2016, 3, 1084-1097. (17) Bharmoria, P.; Trivedi, T. J.; Pabbathi, A.; Samanta, A.; Kumar, A. Ionic liquid-induced all- $\alpha$ to $\alpha+\beta$ conformational transition in cytochrome $\mathrm{c}$ with improved peroxidase activity in aqueous medium Phys. Chem. Chem. Phys. 2015, 17, 10189-10199.

(18) Zhou, L.; Chen, X.; Shao, Z.; Huang, Y.; Knight, D. P. Effect of metallic ions on silk formation in the mulberry silkworm, bombyx mori J. Phys. Chem. B 2005, 109, 16937-16945. (19) MacFarlane, D. R.; Tachikawa, N.; Forsyth, M.; Pringle, J. M.; Howlett, P. C.; Elliott, G. D.; Davis, J. H.; Watanabe, M.; Simon, P.; Angell, C. A. Energy applications of ionic liquids Energy Environ. Sci. 2014, 7, 232-250. 
(20) Lu, J.; Yan, F.; Texter, J. Advanced applications of ionic liquids in polymer science Prog. Polym. Sci. 2009, 34, 431-448.

(21) Lu, S.; Wang, X.; Lu, Q.; Zhang, X.; Kluge, J. A.; Uppal, N.; Omenetto, F.; Kaplan, D. L. Insoluble and flexible silk films containing glycerol Biomacromolecules 2010, 11, 143-150.

(22) Susan, M. A. B. H.; Kaneko, T.; Noda, A.; Watanabe, M. Ion gels prepared by in situ radical polymerization of vinyl monomers in an ionic liquid and their characterization as polymer electrolytes J. Am. Chem. Soc. 2005, 127, 4976-4983.

(23) Jia, X.; Yang, Y.; Wang, C.; Zhao, C.; Vijayaraghavan, R.; MacFarlane, D. R.; Forsyth, M.; Wallace, G. G. Biocompatible ionic liquid-biopolymer electrolyte-enabled thin and compact magnesium-air batteries ACS Appl. Mater. Inter. 2014, 6, 21110-21117.

(24) Lu, Q.; Hu, X.; Wang, X.; Kluge, J. A.; Lu, S.; Cebe, P.; Kaplan, D. L. Water-insoluble silk films with silk I structure Acta Biomater. 2010, 6, 1380-1387.

(25) Cao, Y.; Wang, B. Biodegradation of silk biomaterials Int. J Mol. Sci. 2009, 10, 15141524.

(26) Kong, Y.; Wang, C. Y.; Yang, Y.; Too, C. O.; Wallace, G. G. A battery composed of a polypyrrole cathode and a magnesium alloy anode-toward a bioelectric battery Synth. Met. 2012, 162, 584-589.

(27) Wang, B. Recent development of non-platinum catalysts for oxygen reduction reaction $J$. Power Sources 2005, 152, 1-15.

(28) Rahman, M. A.; Wang, X.; Wen, C. High energy density metal-air batteries: a review J. Electrochem. Soc. 2013, 160, A1759-A1771.

(29) Brenckle, M. A.; Cheng, H.; Hwang, S.; Tao, H.; Paquette, M.; Kaplan, D. L.; Rogers, J. A.; Huang, Y.; Omenetto, F. G. Modulated degradation of transient electronic devices through multilayer silk fibroin pockets ACS Appl. Mater. Inter. 2015, 7, 19870-19875. 
(30) Brenckle, M. A.; Partlow, B.; Tao, H.; Kaplan, D. L.; Omenetto, F. G. Interface control of semicrystalline biopolymer films through thermal reflow Biomacromolecules 2013, 14, 2189-2195.

(31) Lee, Y.; Bang, S.; Lee, I.; Kim, Y.; Kim, G.; Ghaed, M. H.; Pannuto, P.; Dutta, P.; Sylvester, D.; Blaauw, D. A modular $1 \mathrm{~mm}$ die-stacked sensing platform with low power i c inter-die communication and multi-modal energy harvesting IEEE J. Solid-State Circuits 2013, 48, 229-243.

(32) Hwang, S. W.; Kang, S. K.; Huang, X.; Brenckle, M. A.; Omenetto, F. G.; Rogers, J. A. Materials for programmed, functional transformation in transient electronic systems $A d v$. Mater. 2015, 27, 47-52.

(33) Brenckle, M. A.; Partlow, B.; Tao, H.; Applegate, M. B.; Reeves, A.; Paquette, M.; Marelli, B.; Kaplan, D. L.; Omenetto, F. G. Methods and applications of multilayer silk fibroin laminates based on spatially controlled welding in protein films Adv. Funct. Mater. 2016, 26, 44-50.

(34) Vepari, C.; Kaplan, D. L. Silk as a biomaterial Prog. Polym .Sci. 2007, 32, 991-1007. (35) Yin, L.; Cheng, H.; Mao, S.; Haasch, R.; Liu, Y.; Xie, X.; Hwang, S. W.; Jain, H.; Kang, S. K.; Su, Y.; Li, R.; Huang, Y.; Rogers, J. A. Dissolvable metals for transient electronics Adv. Funct. Mater. 2014, 24, 645-658.

(36) Longmire, M.; Choyke, P. L.; Kobayashi, H. Clearance properties of nano-sized particles and molecules as imaging agents: considerations and caveats Nanomedicine 2008, 3, 703-717. 